Much chemical apparatus and many general exhibits are also shown, but it is only possible to mention one or two, such as Messrs. Brunner Mond's phase rule models, Dr. F. Mollwo Perkin's display of oils from the low temperature carbonisation of coal, torbanite, lignite, and other carbonaceous products, while Dr. J. Newton Friend deals with the intricate subject of the rusting and corrosion of metals. There is also a particularly interesting collection, from the Royal Institution, of apparatus used by the late Sir James Dewar.

Finally the photographic section will be found to be of the greatest interest and assistance to devotees of this art.

\title{
Progress in Biology. ${ }^{1}$
}

\section{By W. Bateson, F.R.S.}

$\mathrm{W}^{\mathrm{H}}$ have reached contemporary developments. The study of variation, and indeed of several branches of what we now call genetics, especially crossbreeding, had been pursued with vigour in the 'sixties and 'seventies, but had totally lapsed. Renewal of those inquiries led at once to an advance. We saw that the received ideas as to the magnitude of variations, and especially as to the interrelations of the domesticated breeds, were largely erroneous. As in regard to the incidence of sterility in interspecific crosses, so in regard to variation, we found ourselves among an intricate mass of empirical observations, obeying none of the principles which the orthodoxy of the time presupposed. The incidence of variation was utterly capricious, and was determined neither by utility, nor the antiquity of the feature, nor by the conditions of life, nor by any other ascertainable circumstance.

Most of the genetical work of the early time had been perfunctory and unsystematic. Godron, Naudin, Verlot, Carrière, Morren, and many more, had all seen interesting things, but they had not looked close enough. A single man, Mendel, had worked in a different fashion. Again, by one small bit of clean experimenting, a fact of a new class had been discovered. The evidence of this new witness showed us whole ranges of phenomena in their right perspective and proportions. We had at once a rationale which disposes of such outstanding mysteries as reversion and the determination of sex. Only those who remember the utter darkness before the Mendelian dawn can appreciate what has happened. Stories which then seemed mere fantasies, are now common sense. When I was collecting examples of variation in 1890 , I remember well reading the fanciers' tales about dun tumbler pigeons being almost always hens, and about the "curious effects of crossing" with cinnamon canaries, but I would never have dared to repeat them, any more than Darwin ventured to quote Girou de Buzareingues ( 1828 ) to the effect that in cattle the milking-character was mainly transmitted by the bulla proposition with which the researches of Pearl and others have now made us familiar.

Though Mendelian analysis has done all this, and very much more of which I will presently speak, it has not given us the origin of species. It has finally closed off a wrong road. I notice that certain writers who conceive themselves to be doing a service to Darwinism, take thereupon occasion to say that they expected as much, and that from the first they had disliked the whole thing. I would remind them that the class of evidence to which we were appealing was precisely that to which Darwin and every other previous

1 Continued from p. 646 . NO. 2845 , VOL. I I 3$]$ evolutionist had appealed. Mendelian analysis led to the discovery of the transferable characters, not merely in sporadic instances but as a group, and the study of their behaviour enabled us to avoid endless misinterpretations into which our predecessors had consistently fallen. If we now have to recognise that the transferable characters do not culminate in specific distinctions, the acknowledgment will not come from us alone. The old belief of systematists that real species differ from each other in some way not attainable by summation of varietal characters is no longer contestable, and we know now upon what to concentrate. It is no occasion for dismay. We have not to go back very far. We do not understand specific differences, nor can we account for the adaptative mechanisms. Was it to be expected that we should? Biology is scarcely a century old, and its intensive study is of yesterday. There is plenty of time ahead.

The identification of the transferable characters and their linkages has led to a further discovery of the greatest-I might almost say, of romantic-brilliancy, which must have consequences as yet inestimable. Morgan and his colleagues have, as is well known, proved that some, probably all, of this group of characters are determined by elements transmitted in or attached to the chromosomes. It may be, as Bridges has indicated in regard to sex, that the visible distinctions are produced not so much by the presence or absence of a bit of special chromosome material, as of an interaction between the several chromosomes as a whole, and much depends on that issue; but however that may be, henceforth the study of evolution is in the hands of the cytologists acting in conjunction with the experimental breeder. As to what the rest of the cell is doing, apart from the chromosomes, we know little. We think that in plants the presence or absence of chloroplasts may be a matter of extra-nuclear transmission. Perhaps the true specific characters belong to the cytoplasm, but these are only idle speculations.

While all this has been going on we learn of advances developing from a totally different quarter-palæontology. Those whose work has lain in other fields can form only a dim and tentative understanding of these new lines of discovery. We look eagerly to the palæontologists for a full exposition. We have heard that they, especially the group of investigators connected with the American Museum, have collected wonderful series, in numbers hitherto never attainable, ranging through many geological epochs, demonstrating a continuity of succession between very dissimilar forms of life. For an introduction to this subject I am greatly indebted to Prof. D. M. S. Watson. In 
connexion with these observations we hear frequent use of the term orthogenesis, a word introduced by Eimer to express the notion that evolution proceeds along definitely directed lines. ${ }^{2}$ Eimer was both a vigorous opponent of natural selection and a confirmed Lamarckian. His idea had been enunciated at various times by others, but in spite of a superficial attractiveness such short cuts have seemed too facile, and to be avoided in the absence of irresistible evidence that they are right. Nevertheless, what we have learned of variation, especially of the incidence of parallel variations, has taught us that many varietal forms owe their origin to a process of unpacking a definite pre-existing complex, with the consequence that, given the series of varieties to which one species is liable, successful predictions may sometimes be made as to the terms which will be found in allied series. This is not what is meant by orthogenesis, but the phenomena have features in common.

These symptoms of order in variation have prepared our minds, and there may well be a sense in which orthogenesis will be found to denote a valid principle. Granting that a gradual and secular evolution in one direction is demonstrated, much turns on the evidence that can be produced as to the other variations by which these changes have been accompanied. We anxiously await such details. Especially are we curious as to the nature of the characters concerned. Are they such as in our contemporary experiments we have found to be transferable, and thus likely to be subject to clean segregation? Secondly-a question much more difficult to answer - is it possible that, though undoubted as indications of the course of an actual evolution, the most positive indeed which can be imagined, they should be interpreted as evidence of the origin of species in that stricter sense to which genetics has introduced us?

A sound analytical classification of the several kinds of characters in respect of their modes of variation is greatly to be desired. We have determined the transferable characters as one group, and we no longer confound them with the essential elements

\footnotetext{
2 Artbildung $u$. Verwandschaft bei den Schmetterlingen, ii., I895, p. 3.
}

conferring specificity. Segregation is of course often seen in species crosses, but as to the behaviour of these critical elements we know as yet very little.

Of a third group we may presently learn from the palæontologists. Independent of all these substantive characters we shall distinguish what I have called the Meristic group, as a fairly homogeneous class of phenomena recognisable without much difficulty though still not precisely defined.

That is a place to which I always look for one of the great discoveries about the nature of life. The phenomena of Meristic repetitions, especially in their most obvious manifestations as seen in simple patterns, would appear to be amenable to analysis. Who can look at the stripes on a zebra's hide-to take one of a thousand such illustrations-and not see them as a series of waves? Further, who can compare the hide of Equus zebra with that of Equus grevyii and not see that in E. grevyii the wave-length of the same vibrations is approximately halved? It is in the analysis of pattern that mathematical treatment might properly be applied to biology. If some physicist would examine our patterns and, treating the problem as one of ordinary mechanics, set himself to consider how the forces must be disposed to produce those patterns, I am not without hope that he might find a clue to the nature of the forces themselves.

The future of biology lies not in generalisation, but in closer and closer analysis. It is the lack of analytical penetration that we so miss in the nineteenth-century evolutionists. Phenomena the most diverse are confounded together and discussed under some common name, for example, variation. Their aim is always to unify, never to distinguish. Never are we reminded that every appeal must ultimately be to the mechanics of cell-division. That is the one true and logical unification. The cell, as Cuvier said of the living organism long ago, is a vortex of chemical and molecular change. Matter is continually passing through this system. We press for an answer to the question, How does our vortex spontaneously divide? The study of these vortices is biology, and the place at which we must look for our answer is cell-division.

\section{The Toronto Meeting of the British Association.}

$\mathrm{A}^{\mathrm{R}}$

RRANGEMENTS for the Toronto meeting of the British Association are already well advanced. The meeting will open on Wednesday, August 6, with the installation of Sir David Bruce as president in succession to Sir Ernest Rutherford, and the delivery of the new president's address on advances in our knowledge of disease and the means of coping with and preventing it, with special reference to preventive measures used during the War. The meeting will continue until August I3; meanwhile, the International Mathematical Congress will have begun in Toronto on August $x x$, and on the mathematical, physical, and engineering sides especially, there will be an unique opportunity for co-operation.

The number of members intending to go to the meeting from Britain is at present about 500, and the majority will be sailing on the Cunard liner Caronia, leaving Liverpool on July 26, the Canadian Pacific steamer Montrose and the White Star Megantic from the same port on July 25, and the Melita (Canadian Pacific) from Southampton on July 24 ; but several other vessels will add their quota to the party, as some members are finding occasion to visit points in Canada or the United States, in advance of the meeting. The shipping companies are co-operating closely with the office of the Association in making the best arrangements possible for members ; in particular, the Cunard Company is sending an officer from Liverpool to accompany the party on the Caronia, and to attend the meeting. The local executive committee of the Association in Toronto, under the chairmanship of Prof. J. C. McLennan, is at work arranging accommodation for visiting members, and the secretary of the Association has visited the city and discussed details of the whole organisation with the numerous active workers on the spot. There could not well be a finer situation for an Association meeting. Even the severe demands which the Association makes upon accommodation for its

$$
\text { NO. } 2845 \text {, VOL. I I } 3 \text { ] }
$$

